\title{
DEVER E INCLINAÇÃO EM KANT E SCHILLER
}

\section{DUTY AND INCLINATION IN KANT AND SCHILLER}

\author{
CHARLES FELDHAUS ${ }^{1}$ \\ (Universidade Estadual de Londrina, Brasil)
}

\begin{abstract}
RESUMO
Este estudo ocupa-se com o debate entre Kant e Schiller a respeito do papel das inclinações e do dever na moralidade. Baseando-se em um epigrama de Schiller muitos críticos da ética de Kant afirmaram que Kant não oferece nenhum lugar aos sentimentos na ética. Entretanto, esse cenário tem mudado nos últimos anos com vários membros da Kant-Forschung ressaltando o papel que Kant confere a virtude e aos sentimentos em suas obras tardias e que a obra Sobre graça e dignidade seria aquela em que se poderia melhor identificar a posição de Schiller em relação à ética de Kant. Por conseguinte, esse estudo busca mostrar como dever e inclinação ocupa um papel importante nas concepções éticas de Schiller e Kant. Além disso, Schiller suscita algumas críticas à ética de Kant e esse estudo busca esboçar algumas respostas de Kant a essas objeções em obras como A metafísica dos costumes, Vorarbeiten zur Religion e Vorlesungen zur Moralphilosophie.
\end{abstract}

Palavras-chave: Ética. Dever. Inclinação. Virtude.

\begin{abstract}
This study deals with the debate between Kant and Schiller about the role of the inclinations and the duty in morality. Based on an epigram of Schiller many critics of the ethics of Kant said that Kant offers no place to feelings in ethics. However, this scenario has changed in recent years with several members of the Kant-Forschung highlighting the role that Kant gives virtue and feelings in his later works. Now it is a commomplace to identify the position of Schiller regarding the ethics of Kant with what Schiller said in his work Über Anmut und Würde. Therefore, this study seeks to show how duty and inclination plays an important role in the ethical conceptions of Schiller and Kant. Moreover, Schiller raises some objections against the ethics of Kant and this study aims to outline some answers from Kant to these objections in works such as The Metaphysics of Morals, Vorarbeiten zur Religion and Vorlesungen zur Moralphilosophie.
\end{abstract}

Keywords: Ethics. Duty. Inclination. Virtue.

Introdução $^{2}$

Muitos defensores da ética de virtudes contemporânea queixam-se rotineiramente da ausência de um tratamento substantivo do papel dos sentimentos e da virtude na ética de Kant. Os membros da Kant-Forschung, por sua vez, tem buscado mostrar que Kant ofereceu um papel mais amplo aos sentimentos na ética em obras tardias como A metafísica dos costumes (1797) e A religião dentro dos limites da simples razão (1794). Essa objeção de que a ética de Kant não teria dado um papel adequado aos sentimentos e à virtude na ética remonta a um epigrama de Schiller, denominado escrúpulo da consciência, o qual dá a entender que na ética de Kant, a fim 
de cumprir o dever moral, um ser humano precisaria agir contra suas inclinações, o que para grande parte desses críticos seria uma evidência do caráter moralmente repugnante de uma ética baseada apenas na noção de dever.

Desse modo, esse estudo pretende reconstruir o debate entre Kant e Schiller a respeito do papel das inclinações na conduta moral buscando mostrar que o epigrama escrúpulos da consciência não representa a visão de Schiller a respeito da concepção moral de Kant (I); que as principais críticas de Schiller à ética de Kant encontram-se em Sobre graça e dignidade (II); mostrar mediante exemplos em que consiste a diferença entre Kant e Schiller na atribuição de valor moral (III); apontar quais são as respostas de Kant às objeções de Schiller (IV) e tentar esboçar em que consiste a diferença entre as concepções éticas de Kant e Schiller (V). Quanto às respostas de Kant a Schiller, gostaria de distinguir entre a resposta explícita e o que, eu chamaria de uma resposta implícita, ou que segue o espírito da filosofia moral de Kant. A resposta explícita de Kant aparece na nota da segunda edição de $A$ religião dentro dos limites da simples razão e nas anotações de aula do semestre que se seguiu à publicação de Sobre graça e dignidade de Schiller, Metaphysik der Sitten Vigilantius. Se poderia afirmar sem medo de errar que existe uma resposta explícita, mas sem menção ao nome de Schiller em $A$ metafísica dos costumes, onde Kant trata da moral ascética. Da mesma maneira, se poderia encontrar respostas explícitas de Schiller a Kant, ou ao menos, comentários em que ele deixa claro algum tipo de filiação em relação à filosofia moral de Kant ou à filosofia de Kant em geral ao menos.

\section{O epigrama escrúpulos da consciência e equívocos interpretativos}

Embora tenha sido uma tendência interpretar esse epigrama de Schiller como a verdadeira posição dele a respeito da ética de Kant, nos últimos anos tem havido uma tendência a interpretar a posição de Schiller em Sobre graça e dignidade (1794), para identificar sua posição em relação à ética de Kant e interpretar o epigrama como apenas um meio de satirizar aqueles que interpretavam Kant como retratado no epigrama. Que esse epigrama expressa uma visão errônea a respeito do pensamento moral de Kant é fácil perceber, e exige que apenas se preste atenção ao objetivo e à tipologia das ações que ele desenvolve em A fundamentação da metafísica dos costumes (1785). Quanto à tipologia, os críticos deveriam prestar atenção ao fato que Kant distingue entre agir por dever, agir contrário ao dever, agir conforme ao dever e agir por inclinação (imediata ou 
mediada). Nessa tipologia, a presença ou ausência de inclinações não é a marca distintiva quer de ações morais, quer de ações imorais. O ponto central aqui é que as inclinações não são uma marca distintiva da moralidade ou da imoralidade de uma ação na concepção moral de Kant. Nessa tipologia, ações imorais podem ser motivadas por inclinações e ações conforme ao dever podem ser motivadas por inclinações. A presença de inclinações não torna as ações imorais, como o epigrama poderia sugerir. Como dizem Schönecker \& Wood (2002, p. 70), Kant não está dizendo que "temos que odiar nosso amigo ou de algum modo promover inclinações contrárias ao dever, apenas para nos dar a oportunidade, de contradizer tais inclinações". E é importante ressaltar que Schiller, o autor do epigrama, reconhece isso em Sobre graça e dignidade, quando afirma que a participação das inclinações em uma ação livre não prova nada a respeito da conformidade ao dever [Pflichtmäßigkeit] da mesma, embora ele também reconheça que a participação das inclinações seria importante para esclarecer [erhellen] a perfeição ética [die sittliche Vollkommenheit] (Schiller 1971, p. 106). Pode-se dizer que aqui existe uma diferença na compreensão do âmbito da ética em Kant e Schiller, a saber, Kant se ocupa com o valor moral das máximas de ações e Schiller com o valor moral do caráter. Entretanto, Kant também trata da virtude e dos sentimentos morais nas obras da década de 1790, principalmente em $A$ metafísica dos costumes e que a noção de máximas ocupa papel central na concepção de virtude em $A$ religião dentro dos limites da simples razão. Kant apresenta na introdução a Tugendlehre vários sentimentos morais (em contraste com patológicos) como pré-conceitos estéticos [ästhetische Vorbegriffe] relativos à receptividade [Empfänglichkeit] do ânimo ao conceito de dever: sentimento moral [moralische Gefühle], consciência moral [Gewissen], amor ao próximo [Liebe des Nächten] e respeito [Achtung] (A. A. VI, 398-403) ${ }^{3}$. Além disso, o sentimento patológico de simpatia ocupa um papel relevante no cumprimento de certos deveres em A metafísica dos costumes, como o dever de beneficência (A. A. VI, 456-7).

Em Sobre graça e dignidade, Schiller sustenta que "a ideia de dever [em $A$ fundamentação da metafísica dos costumes e na Crítica da Razão Prática (1788)] é exposta com uma severidade (Schiller 1971, p. 107) que inclusive poderia induzir a um entendimento fraco a seguir o caminho de uma moral ascética e monástica. O que Schiller deixa claro que seria uma falsa interpretação [Mißdeutung] do pensamento ético de Kant (Schiller 1971, p. 107). Schiller acredita que a escolha de Kant desse tipo de exposição pode ser explicada a partir das circunstâncias históricas em que ele viveu, a 
saber, deparou-se com um materialismo grosseiro [ein grober Materialismus] e com teorias éticas baseadas no princípio da perfeição [Perfektionsgrundsatz] (Schiller 1971, p. 107-8). Diante disso, Schiller afirma que Kant concentrou suas forças onde o perigo era mais declarado, ou seja, contra a sensibilidade, contra o materialismo na moral. Além disso, em Sobre a educação estética do homem em uma série de cartas (1795), Schiller afirma que em uma filosofia transcendental como a de Kant seria fácil habituarse a compreender os sentimentos como empecilhos e a sensibilidade como necessariamente entrando em contradição com a lei moral, entretanto, por mais que "tal maneira de apresentação não se encontre de fato no espírito do sistema kantiano [im Geist des Kantischen Systems], mas pode encontrar-se em sua letra [im Buchstaben]“ (Schiller 2009, p. 52).

\section{As críticas de Schiller a ética de Kant}

Kant tomou conhecimento das críticas de Schiller à sua filosofia moral mediante uma carta de Lohann Erich Biester de 05 0utubro de 1793. Aqui Biester afirma que Kant deveria prestar atenção ao que Schiller diz em Sobre graça e dignidade, em que Schiller se refere ao sistema moral de Kant como "aquele em que a dura voz do dever parecia tão fortemente (como uma lei prescrita pela própria razão mas todavia como uma lei estranha) e em que existe pouca atenção à inclinação”. (A. A. XI, 456-7). Ao publicar a segunda edição A religião dentro dos limites da simples razão, Kant responde às críticas de Schiller. Aqui Kant responde em tom bastante conciliatório, contudo, ressalta que Schiller critica sua filosofia moral por apresentar o conceito de obrigação [Verbindlichkeit] como se [als ob] levasse a uma determinação cartusiana do ânimo [eine kartäuserartige Gemüthstimmung]. A despeito disso, Kant acrescenta que ambos estariam de acordo a respeito dos princípios fundamentais e, que, para resolver as diferenças entre ambos se exigiria apenas que ambos se fizessem melhor entender mutuamente (A.A. VI, 24, nota). Não obstante, Kant confessa que ele não consegue entender como o conceito de dever [Pflichtbegriffe] pode ser harmonizado com o conceito de graça [Anmut] (A.A. VI, 24, nota). Kant parece aqui jogar o ônus da prova a Schiller. Até porque esse ponto consiste na pedra fundamental da posição ética de Schiller, sem o qual a própria figura da bela alma seria impossível. A estratégia inicial de Kant nessa nota é semelhante àquela adotada em A fundamentação da metafísica dos costumes para recusar os sentimentos como princípio supremo da moralidade, a saber, 
chamar a atenção ao fato que enunciados morais são marcados pela necessidade incondicional, ao passo que sentimentos poderiam ser apenas a base de necessidade condicional (imperativos hipotéticos) (A. A, IV, 400-1).

Schönecker \& Wood (2002, p. 71, nota) consideram que não haveria nenhuma contradição entre as posições de Kant e Schiller, a despeito do polêmico epigrama supracitado e que Kant teria respondido a crítica de que sua ética tinha a aparência de uma determinação cartusiana do ânimo no final da própria nota de $A$ religião dentro dos limites da simples razão observando que a virtude exige "o coração alegre [das fröhliche Herz] no cumprimento do dever" (A. A. VI, 24, nota). Kant ocupa-se novamente em responder essa objeção em Tugendlehre (§ 53) ao tratar da moral ascética e oferece uma resposta mais detalhada, qual será elucidada mais adiante no presente estudo.

Entretanto, Schiller afirma que a forma imperativa da lei moral, tal como expressa na filosofia de Kant pode levar a moralidade a tomar uma aparência de uma lei estranha e positiva (Schiller 1971, p. 109). Razão pela qual Reed Winegar (2013, p. 277-8) sustenta que a resposta de Kant a Schiller seria baseada no sentimento do sublime e consistiria em mostrar que a lei moral não se apresenta aos seres humanos com essa aparência estranha e positiva como esse tipo de passagem de Schiller parece sugerir. Além do mais, Schiller desenvolve uma teoria moral própria em que procura integrar sensibilidade e razão, inclinação e dever. No centro dessa concepção ética encontra-se a figura da bela alma [die schöne Seele]. Possui uma bela alma aquele ser humano "em que o sentimento ético assegurou que todas as sensações do ser humano finalmente até o grau em que aos afetos se pode deixar a direção da vontade sem receio e sem correr perigo de entrar em contradição com as decisões da mesma" (Schiller 1971, p. 111). É importante apontar que Schiller não acredita que sempre seja possível cumprir o dever com a leveza de uma bela alma, como se o dever fosse cumprido por instinto (Schiller 1971, p. 111). Até porque ele acredita que a bela alma consiste apenas em uma ideia [bloß eine Idee], a qual nunca pode ser plenamente alcançada (Schiller 1971, p. 113). Por causa disso, Schiller apresenta outra figura, que possui apenas uma disposição sublime [erhabenen Gesinnung], a figura da dignidade [Würde]. Nesses casos, dos quais Schiller diz que as situações trágicas da vida seriam exemplos, não seria possível uma consonância entre a lei da razão e as exigências da sensibilidade, e por conseguinte, nenhuma consonância entre dever e inclinação (Schiller 1971, p. 118). 
Ele ressalta, contudo, que esse tipo de ato não possui beleza [Schönheit], o ser humano não age de modo moralmente belo [moralisch schön], mas apenas de modo moralmente grande [moralisch groß] (Schiller 1971, p. 118-9).

\section{As concepções éticas de Kant e Schiller e o dever de beneficência ou filantropia}

A fim de contrastar o papel das inclinações e da lei moral nas concepções morais de Schiller e Kant, será apresentado como Schiller e Kant avaliam moralmente casos de filantropia. Kant aplica sua teoria moral a casos de filantropia em $A$ fundamentação da metafísica dos costumes e em A metafísica dos costumes, ao passo que Schiller aplica sua concepção de beleza moral a casos de filantropia em Kallias Briefe e Sobre a educação estética do homem em uma série de cartas.

Em Kallias Briefe, Schiller apresenta um exemplo, a fim de ilustrar seu conceito de beleza moral, o que chamou de bela alma em Sobre graça e dignidade. Schiller acredita mostrar também com esse exemplo que a liberdade na aparência [die Freiheit in der Erscheinung] é possível. O caso abordado consiste em uma reformulação da parábola do bom samaritano (Lucas 10, 25-37). Ele imagina um homem que foi saqueado e deixado nu para morrer à beira da estrada em um dia com baixa temperatura. Primeiramente, aparece um homem que diz compartilhar o sofrimento e que se oferece para ajudar, mas sente repulsa em olhar para o estado em que ele se encontra à beira da estrada, então oferece dinheiro para que ele pague a próxima pessoa que aparecer para lhe ajudar (Schiller 1971, p. 29). Essa ação não possui nenhuma relação com a lei moral e, por isso, carece de valor moral e carece de beleza para Schiller. Em segundo lugar, aparece um homem que ama muito o seu dinheiro e como perderia dinheiro se parasse para ajudar, diz que ajudaria apenas sob a condição de ser pago para isso (Schiller 1971, p. 29). Ao passo que a primeira ação baseia-se em uma inclinação imediata, essa segunda baseia-se em uma inclinação mediada por outros interesses (dinheiro). Em terceiro lugar, aparece um homem que, a despeito das inclinações em contrário (ele possui apenas a roupa do corpo e está doente), deseja ajudar. Essa ação foi praticada por respeito pela lei moral, mas não possui beleza moral (Schiller 1971, p. 30). Em quarto, aparecem dois homens que se dispõem a ajudar, a despeito das inclinações em contrário (eles desejam vingar-se do homem caído à beira da estrada) (Schiller 1971, p. 30). Finalmente, aparece um homem, que espontaneamente se dispõe a ajudar por inclinação imediata. Essa ação foi praticada por inclinação imediata e está de acordo com a 
exigência do dever, razão pela qual é simultaneamente moral e bela (Schiller 1971, p. 31). A primeira questão que surge aqui diz respeito à hierarquia entre esses diferentes casos. A interpretação natural seria que o valor das ações vai aumentando do primeiro até ao quinto caso. Embora essa classificação não seja isenta de problemas. O segundo caso parece ter menos valor moral do que o primeiro, uma vez que o primeiro deseja ajudar, mas em função de uma inclinação imediata em contrário [unmittelbare entgegengesetzte Neigung], se oferece apenas para pagar para que outra pessoa ajude. $\mathrm{O}$ segundo tem uma inclinação mediada, dado que condiciona a ajuda ao recebimento do dinheiro que perderia, caso praticasse o ato filantrópico. O primeiro se dispõe ajudar sem condições, apenas pretende delegar o ato a outrem em função de inclinação imediata contrária ao que o dever exige. O segundo, embora esteja disposto a ajudar diretamente, condiciona essa ajuda ao recebimento de uma contrapartida. Além do mais, Schiller parece dar a entender que os dois primeiros casos seriam ações conforme ao dever [pflichtmäßige Handlung], na classificação de Kant em A fundamentação da metafisica dos costumes (A. A. IV, 397). O terceiro caso seria claramente uma ação por dever [aus Pflicht]. O quarto caso seria uma ação por dever [aus Pflicht], contudo, com inclinação mediada em contrário [mittelbare entgegengesetzte Neigung], a saber, o desejo de vingança por algo que anteriormente havia sido praticado. O que sugere que, segundo Schiller, um ato por dever, com inclinação contrária ao dever, possui mais valor moral que um ato por dever sem nenhuma inclinação (ao menos nenhuma inclinação foi mencionada nesse segundo caso). Esse ponto aproxima de alguma forma novamente Kant e Schiller, uma vez que Kant disse em A metafisica dos costumes, define a virtude como "força da máxima do ser humano no cumprimento do dever" (A. A. IV, 271) e a maneira como se pode medir essa força consiste nos obstáculos [Hindernisse] que se consegue superar [überwältigen] no cumprimento do dever. O quinto e último caso trata-se de uma ação por dever (principium dijudicationis) e por inclinação imediata favorável ao dever (principium executionis). Schiller diz, na carta de 19 de fevereiro de 1793, que o quinto "cumpriu o seu dever com uma leveza, como se o simples instinto tivesse agido" (Schiller 1971, p. 32). Kant, em sua resposta na segunda edição de $A$ religião dentro dos limites da simples razão afirma que "o coração alegre no cumprimento do seu dever (...) é um indício da autenticidade da disposição virtuosa" (A. A. VI, 24, nota). Entretanto, cumprir o dever com um coração alegre e cumprir o dever por instinto e com a leveza de uma bela alma são distintos. A bela alma cumpre o 
dever sem o experimentar como um imperativo, mesmo aquele que cumpre o dever com coração alegre continua a obedecer a lei moral em forma imperativa.

Como já dito, Kant ocupa-se com casos de filantropia em A fundamentação dentro dos limites da simples razão (A.A. IV, 398-9). Primeiramente, ele apresenta um ser humano que teria uma inclinação natural em espalhar alegria a sua volta, sem nenhuma vantagem pessoal. Ele ressalta que esse tipo de conduta, embora conforme ao dever [pflichtmäßig] e louvável [liebenswürdig] carece de verdadeiro valor moral (A. A. IV, 398). O verdadeiro valor moral de uma ação se encontra em realizar algo não por inclinação [aus Neigung], mas por dever [aus Pflicht]. Na sequência, Kant modifica o exemplo e supõe agora que a natureza não foi tão favorável a esse ser humano e, em vez de uma inclinação a espalhar a alegria a sua volta, ele tivesse pouca simpatia [Sympatie] e um temperamento frio [Temperament kält] (A. A. IV, 398). Agora, se apesar de todas as inclinações contrárias, mesmo assim ele praticasse um ato de filantropia, não por inclinação, mas motivado pelo respeito pela lei moral, exatamente nisso estaria o valor do seu caráter (A. A. IV, 398-9).

É importante observar aqui, que nem Schiller nem Kant pensam que o filantropo natural seria um modelo de bondade ou beleza moral. Kant pensa que apenas um ato motivado pelo respeito pela lei moral tem verdadeiro valor moral. Novamente, Kant não está dizendo com isso que um ato praticado "com inclinações” favoráveis ao dever seria imoral. Ele deixa claro que seria conforme ao dever e louvável. Além disso, Kant diferencia em Vorlesungen zur Moralphilosophie, Collins (A. A. , XXVII, 463) entre ser virtuoso, ser vicioso e não possuir a virtude: "é apenas que se não se pratica a lei moral; (...) o ser humano, que não é virtuoso, mas por causa disso não é ainda vicioso", ou seja, se careço da virtude não sou vicioso, sou carente de virtude [untugenhaft]. Schiller pensa que os seres humanos dotados com bom coração [guten Herzen] e com temperamento virtuoso [Temperamentstugend] não são o padrão de beleza moral, ou seja, eles não são a mesma coisa que uma bela alma (Schiller 1971, p. 119). Mas então qual seria a diferença entre Kant e Schiller na avaliação de um ato de filantropia? Aqui é oportuno observar que Schiller em nota a XIII carta de Sobre a educação estética do homem em uma série de cartas, trata do efeito maléfico do predomínio quer do impulso sensível [Sachtrieb], quer do impulso formal [Formtrieb]. Ao tratar do efeito maléfico do predomínio do impulso formal na filosofia prática, ele também trata do caso da filantropia e afirma que é preciso harmonizar sentimento e caráter, mas também que “como podemos ainda ser dignos de louvor, bondozos e humanos se faltar a faculdade 
de aprender fiel e verazmente a natureza do outro (...) de tornarmos nosso o sentimento alheio?" (Schiller 2009, p. 54-5). Kant em Tugendlehre trata da simpatia [Mitfreude und Mitleid] (sympathia moralis) (A. A. VI, 456-7). Kant entende cultivar o sentimento natural da simpatia como um dever indireto (A.A. VI, 457).

Schiller também acredita que a forma imperativa da ética se aplica apenas aos servos [Knechte], mas não aos filhos da casa [die Kinder des Hauses]. Ou seja, a lei moral somente se apresenta na forma imperativa para aquele que ainda não cultivou seus sentimentos de modo a cumprir o dever de maneira espontânea e leve como uma bela alma (Schiller 1971, p.109). Schiller acredita que, "porque o fracote moral [der moralische Weichling] quer dar a lei da razão uma lassidão (...) por isso não se deve atribuir a ela uma rigidez". Schiller entende que uma moral imperativa se aplica apenas aqueles que não cultivaram sua sensibilidade, a fim de cumprir com alegria e prazer aquilo que a lei moral exige. Ou seja, a forma imperativa da ética não se aplica a todos. Aqui se encontra sem dúvida uma diferença entre a filosofia moral de Kant e a de Schiller, uma vez que Kant afirma explicitamente que a lei moral sempre se apresenta aos seres racionais finitos na forma imperativa (A. A. IV, 414).

Além disso, Schiller sustenta que a avaliação moral da conduta humana refere-se não às ações individuais, mas ao ser humano como um todo, não a praticar uma ação moral individual, mas a ser um ser ético [sittliches Wesen]. (Schiller 1971, p. 106) Aqui se pode dizer que se encontra uma possível diferença entre o pensamento ético de Kant e Schiller, ao menos comparando Sobre graça e dignidade e A fundamentação da metafisica dos costumes. Kant em 1785 ainda não discute o papel dos sentimentos e da virtude na ética de maneira tão clara como faz em Crítica da razão prática, em $A$ religião dentro dos limites da simples razão e em A metafísica dos costumes. Entretanto, se poderia sustentar que seria uma diferença de ênfase e não uma diferença substancial, uma vez que Kant ainda não trata do papel dos sentimentos morais e não morais (ou patológicos) na ética e das virtudes em suas duas principais obras de ética da década de 1780, embora ele trate desse tema em obras da década de 1790, sem contar que o objetivo de A fundamentação da metafísica dos costumes (A. A. IV, 392) é a identificação e o estabelecimento do princípio supremo da moralidade apenas.

Em A metafísica dos costumes, Kant desenvolve sua concepção de virtude [Tugend] "como a força das máximas do ser humano no cumprimento do seu dever" (A. A. VI, 394). Em outras passagens, Kant se refere à virtude como força moral [die 
moralische Stärke] da vontade no cumprimento do dever (A. A. VI, 405) ou ainda como domínio sobre si mesmo [der Herrschaft über sich selbst], o que ele identifica com liberdade interior [innerer Freiheit] e não se deixar dominar pelos seus sentimentos e inclinações, o dever de apatia moral (A. A. VI, 408). A virtude é um estado de saúde da alma (A.A. VI, 409). É importante observar que assim como o valor moral das máximas das ações em $A$ fundamentação da metafísica dos costumes podem ser melhor avaliados do ponto de vista moral, quando o ser humano possui inclinações contrárias ao que o dever exige, também a força, a que se refere a virtude, é melhor conhecida pelos obstáculos que se é capaz de superar no cumprimento do dever (A. A. VI, 394). Os obstáculos, a que se refere Kant aqui, são as inclinações naturais [Naturneigungen], que podem entrar em conflito com o propósito moral (A. A. VI, 394). Do que ele conclui que a virtude é uma coerção [Zwang] segundo um princípio da liberdade interna ou até mesmo uma autocoerção [Selbstzwang] ou autocracia. Dessa maneira, Kant teria dois conceitos de liberdade na filosofia moral: o conceito de liberdade como autonomia, exposto principalmente em A fundamentação da metafísica dos costumes, e o conceito de liberdade como autocracia, exposto principalmente em A metafísica dos costumes. Baxley (2010, p. 51-67) afirma que autocracia é diferente de autonomia na medida em que envolve a consciência da capacidade de dominar as inclinações contrárias ao que o dever exige, e por isso seria marca de virtude moral. A autocracia envolve autodomínio e auto-coação, um tipo de liberdade interior. A liberdade como autonomia, por sua vez, tem a ver com a obediência a uma lei moral dada pela própria razão do sujeito agente independente de interesses egoístas.

Schiller em sua obra Über den moralischen Nutzen ästhetischen Sitten fala de dois conceitos de liberdade na esfera moral: a liberdade da ação externa [außernen Handlungen] que pertence à pessoa [Person] e a liberdade interna que pertence à vontade [Wille] (Schiller 1955, p. 310). Nesse texto, Schiller deixa claro que a moral é independente da estética, "a moral não permite nenhum outro fundamento do que si mesma" (Schiller 1955, p. 309). O que chama a atenção nesse texto de Schiller, quando comparado com a filosofia moral de Kant, é que, apesar da recusa de Schiller da tese do mal radical, ele reconhece que o mais forte inimigo [der stärkeste Gegner] da moralidade é uma tendência da faculdade de desejar [Begehrungsvermögen], da vontade [Wille] de ignorar a lei moral e que a principal tarefa do ser humano em sua conduta moral seria lutar contra essa tendência (Schiller 1955, p. 312), mas tratar do mal radical não é o principal objetivo desse estudo. 
Schiller, por sua vez, concebe a virtude como "uma inclinação ao dever" (Schiller 1971, p. 106). Além disso, Schiller diz que possui uma bela alma [eine schöne Seele], portanto a virtude, aquele que tem cultivado "todas as sensações [aller Empfindungen] (...) até ao grau que assegurou, que se pudesse deixar aos afetos a direção da vontade sem receio e sem correr nenhum perigo de que entrassem em contradição" (Schiller 1971, p. 111). Em Sobre graça e dignidade Schiller afirma que o ser humano "não apenas está autorizado a relacionar prazer e dever, mas ele deve; ele deve obedecer a sua razão com alegria" (Schiller 1971, p. 106). Embora ele tenha reconhecido que a objeção de que a ética de Kant rejeitava as inclinações seja errônea, ele sustenta que "nunca mais a razão pode repudiar os afetos [Affekte] como sem valor para ela" (Schiller 1971, p. 110). Schiller sustenta que os sentimentos não podem ser sempre apenas a parte oprimida, mas devem ser também a parte colaboradora nas ações morais.

\section{As respostas de Kant às criticas de Schiller}

No $§ 53$ da Tugendlehre Kant trata da moral ascética e, conforme diz Baxley (2010, p. 1089), mesmo “que não se mencione explicitamente Schiller pelo nome" é notório que Kant parece ter as críticas de Schiller em mente. Primeiramente, Kant diferencia entre exercício da virtude [Übung in der Tugend] e cultura da virtude [Kultur der Tugend] (A.A. VI, 484). Ele ressalta que o exercício da virtude exige duas disposições de ânimo: valentia e alegria de ânimo. Além disso, se pode sustentar que aqui Kant responde à objeção de Schiller de que a lei moral em forma imperativa se apresenta como uma lei positiva e externa (Schiller 1971, p.109). Kant afirma que aquilo que se pratica sem prazer e como se fosse uma escravidão não contem nenhum valor e não apetece, o que inclusive poderia levar as pessoas a uma tendência a evitar o cumprimento do dever. Ou seja, Kant concorda aqui com Schiller que a lei moral não pode se apresentar como uma lei externa e como se fosse uma imposição a um escravo. Depois disso, Kant se dedica à cultura da virtude, a qual ele identifica com a moral ascética. Aqui ele procura responder à acusação mencionada de que sua ética seria um tipo de ascética monástica (Schiller 1971, p. 107). Kant entende que o cultivo da virtude exige apenas manter-se moralmente saudável, ele inclusive chama esse cultivo de dietética [Diätetik] (A.A. VI, 484). Na concepção de moral ascética de Kant (A. A. IV, $85)$, trata-se apenas de lutar contra os impulsos naturais para dominá-los nos casos em 
que eles colocam em risco a moralidade e não contra quaisquer impulsos naturais, uma vez que, como Kant reconhece em $A$ religião dentro dos limites da simples razão, as inclinações naturais não são em si mesmas nem boas nem mas moralmente. É importante observar alguma semelhança nesse ponto com a posição de Schiller, o qual afirma, ao tratar da dignidade, que se a natureza fizer uma exigência e quiser surpreender a vontade com o poder cego do afeto, a razão deve controlar os impulsos naturais e fazer com que apenas a razão volte a ser o princípio que determina o curso correto (a razão sempre deve ser aquilo que Kant denomina o princípio de justificação ou principium dijudicationis mesmo em Schiller) (Schiller 1971, p. 117).

Mas o que pensa Kant a respeito da moral ascética monástica? Ele considera essa visão moral vinculada a um temor supersticioso [abergläubischer Furcht] e a uma aversão hipócrita a si mesmo que leva a autopunição [Selbstpeinigung] e a mortificação da carne [Fleischeskreuzigung] cujo objetivo não seria a virtude, mas a uma expiação fanática [schwärmerische Entsündigung] do pecado (A. A. VI, 485). O principal problema com a moral monástica e que tem mais relevância ao debate entre Kant e Schiller, diz respeito à incapacidade desse tipo de visão ética "produzir a alegria que acompanha a virtude" (A. A. VI, 485). Kant inclusive termina a seção da moral ascética enfatizando que a alegria [Frosinn] seria um sinal distintivo do meritório [verdienstlich] e do exemplar [exemplarisch]. (A. A. VI, 485). Ou seja, assim como Schiller, Kant reconhece que cumprir o dever com contentamento não é marca de ausência de valor moral, mas inclusive pode ser indício de uma conduta virtuosa.

Kant responde explicitamente às críticas de Schiller em Die Vorlesungen zur Moralphilosophie, Metaphysik der Sitten Vigilantius. Esse texto consiste nas anotações de aula dos alunos relativas ao curso que Kant ofereceu no semestre 1793-1794 logo após a publicação de Sobre a graça e dignidade. Aqui Kant claramente adota um tom menos conciliatório do que aquele que adotou na nota da segunda edição de $A$ religião dentro dos limites da simples razão. Além disso, Kant parece compreender a divergência com Schiller como se referindo ao conceito de obrigatoriedade [Verpflichtung], o qual, segundo Kant (A.A. XXVII, 490), sempre estaria associado a algum tipo de coação [Zwang] e que por isso seria contraditório sustentar que ter deveres morais seja algo prazeroso assim como seria errôneo afirmar que a lei moral exija respeito de forma dolorosa e despótica, como seria o caso de uma moral ascética monástica. Kant reconhece que pode surgir algum prazer ou contentamento [Vergnügen] na conduta moral, mas apenas como um resultado da conduta moral e não como um 
motivo, diz Kant: "é verdade, que podemos encontrar prazer na virtude e na contemplação da mesma, mas apenas no momento e pela razão que já temos a habilidade de cumprir deveres morais" (A.A. XXVII, 490). Além do mais, Kant entende que nossa experiência psicológica contraria a visão de Schiller, uma vez que a lei moral se mostra aos seres humanos finitos como dotada de obrigatoriedade [Verpflichtung] e dotada de coação [Zwang] e não algo que surge de um impulso livre [freiem Triebe] (A.A. XXVII, 491). No fundo, o desacordo entre Kant e Schiller encontra-se no próprio conceito de natureza humana que ambos supõem, e Kant deixa claro isso quando diz: "cumprir seu dever por impulso livre: isso apenas encontra-se para além do horizonte da natureza humana" (A.A. XXVII, 491). O que é completamente coerente com a posição de Kant em Crítica da razão prática e mostra que o debate com Schiller não levou a nenhuma reformulação radical do pensamento moral de Kant, mas apenas a esclarecer alguns aspectos de sua concepção moral, principalmente a respeito do tipo de papel que a virtude e o sentimento poderiam ocupar na reflexão moral.

Em outra passagem de Metaphysik der Sitten Vigilantius, Kant novamente refere-se às críticas de Schiller (A.A. XXVII, 623). Novamente Kant chama a atenção à incompatibilidade entre a noção de obrigatoriedade moral [Verpflichtung] e o que Schiller exige da conduta moral. Conforme Barbosa (2005, p. 240), Schiller busca uma convergência em seu ideal de beleza, o que já estaria presente em Sobre graça e dignidade, com o imperativo ético cristão, para superar a visão moral imperativa de Kant, o que inclusive estaria presente em Kallias Briefe, ao reformular o exemplo do bom samaritano do evangelho cristão (Lucas 10, 25-37). Não procurarei examinar aqui a plausibilidade desse tipo de vinculação entre Schiller e o cristianismo. Porém, também é patente como Kant tenta mostrar no texto aqui discutido que a moral não pode se basear em um conceito de amor entendido como patológico, o único amor que pode ser objeto da moralidade é o amor prático. Kant também defende semelhante posição em $A$ fundamentação da metafísica dos costumes e Crítica da razão prática. Kant afirma que “deveres estritos não são compatíveis com amor, a não ser que estejamos postulando uma ética laxa, e tenhamos rejeitado completamente a moral rigorosa" (A.A. XXVII, $623)$.

O que Kant diz mais adiante em Metaphysik der Sitten Vigilantius e em Vorarbeiten zur Religion indica que Kant leu a obra Sobre graça e dignidade de Schiller e não apenas se restringiu a responder a breve reconstrução da crítica de Schiller 
apresentada por J.E. Biester em sua carta de 05 de outubro de 1973. Em Vorarbeiten zur Religion existem citações longas da obra Sobre graça e dignidade intercaladas com comentários do próprio Kant. Além disso, conforme (Santos, 2007, p. 80), Kant leu também Sobre a educação estética do homem em uma série de cartas, uma vez que entre as páginas do que veio a se chamar Opus postumum de Kant, existe ,a transcrição de um longo parágrafo" de uma das cartas de Schiller dessa obra.

Winegar (2013, p. 287) parece estar correto em afirmar que entre as preocupações de Kant ao responder as críticas de Schiller encontra-se mostrar que a lei moral na forma imperativa teria uma aparência de uma lei positiva e externa, quando ele diz que "essa comanda respeito, não subordinação servil" e "nisso se baseia a coerção, porém apenas um sentimento de respeito voluntário está envolvido. Severidade não é de forma alguma pensável, mas dignidade da lei” (A. A. XXVII, 624). Sustento que o que Kant diz aqui poderia ser entendido como uma resposta ao que Schiller afirma em Sobre graça e dignidade (Schiller 1971, p. 106), ao sustentar que sua concepção ética estaria em completo acordo com os rigoristas, mas que ele também não espera com isso tornarse um latitudinário, uma vez que pretende conciliar as exigências da razão e da sensibilidade, as exigências da razão válidas no campo da legislação moral e as exigências da sensibilidade válidas no campo do efetivo exercício do dever ético. Ou seja, Schiller parece entender, como aponta Beiser (2005, p.177), que a razão seria o principium dijudicationis e a sensibilidade o principium executionis. Kant em $A$ fundamentação da metafísica dos costumes claramente atribui à razão o papel de principium dijudicationis e principium executionis. Kant distingue entre principium diiudications e principuim executionis em Vorlesungen zur Moralphilosophie, Mrongovius (A. A. XXVII, 1422-3). O primeiro diz respeito à justificação [Beurtheilung, Bonität] de uma ação, que curso de conduta seria correto seguir, ao passo que o segundo diz respeito à execução [Antrieben, Ausübung, Ausführung] de uma ação. O segundo tem a ver também com a virtude de um ato, uma vez que a virtude trata da força do arbítrio no cumprimento do dever moral, no cumprimento daquilo que o princípio de justificação identificou como o curso de conduta correto a seguir e que poderia não ser realizado, caso as inclinações contrárias ao dever não fossem controladas, esse controle Kant chama de liberdade como autocracia.

Por conseguinte, Kant está defendendo que, em Metaphysik der Sitten Vigilantius, a despeito do que Schiller tenha dito em Sobre graça e dignidade em contrário, que a concepção moral que Schiller advoga não consegue escapar à acusação 
de ser uma concepção ética defeituosa [ethica deceptrix], principalmente exigindo algo que seria desproporcional à moralidade e às capacidades humanas, como seria o caso do ideal de perfeição estóica, conforme diz Kant em Vorlesungen zur Moralphilosophie, Herder (A. A. XXVII,15-16). Entretanto, Beiser pensa que Schiller consegue ser um rigorista quanto ao principium dijudicationis e um latitudinário quanto ao principium executionis, sem cair em contradição (Beiser 2005, p. 173, nota 12), ou seja, a razão determina o curso de conduta o correto a seguir, mas a tarefa de execução é da sensibilidade. Embora a tentativa de Beiser de reconstruir uma interpretação mais aceitável buscando mostrar que Schiller seria um filósofo de grande envergadura na história da filosofia moral seja louvável, ele parece incorrer no mesmo problema do texto de Schiller, a saber, deixar de explicar "como", por exemplo, uma bela alma poder chegar a uma harmonia entre sensibilidade e razão. As considerações a respeito da educação estética terminam sendo bastante gerais e abstratas. Schiller em Sobre a educação estética do homem em uma série de cartas apenas expõe os conceitos de impulsos sensíveis [Sachetrieb] e racionais [Formtrieb], os quais seriam superados num terceiro impulso, o impulso lúdico [Spieltrieb]. Esse seria senão uma harmonia entre os outros dois e não um novo impulso. A cultura [Kultur] seria responsável por desenvolver essa harmonia, que seria uma mútua limitação de ambos os impulsos, uma ação recíproca. O conceito de forma viva [lebende Gestalt] expressa, para Schiller, aquilo que ele compreende como beleza [Schönheit], um equilíbrio [Gleichgewicht] entre os dois impulsos antagônicos. Entretanto, em vez de explicar ou ilustrar como esse equilíbrio seria alcançado mediante a educação estética e pela cultura, Schiller novamente recua, primeiramente, dizendo que esse ideal de beleza e humanidade nunca será concretizado na realidade, na qual apenas se pode obter o predomínio de um ou outro impulso e uma oscilação entre os mesmos. Enfim, permanece uma discussão bastante abstrata, que pouco informa sobre como alcançar a pretensa unidade da natureza humana mediante uma educação estética.

Também é oportuno lembrar, o que Kant diz na nota de $A$ religião dentro dos limites da simples razão aponta nessa direção: "quando o dever é o tema, a graça mantém uma respeitosa distância" (A. A. VI, 23, nota), a saber, Kant compreende que dever e graça não sejam conceitos compatíveis, tentar juntar o conceito de dever e o conceito de graça seria, uma contradictio in adjecto, a saber uma justaposição de dois termos mutuamente contraditórios. Desse modo, se pode dizer que Kant tem claramente 
dois objetivos principais ao responder Schiller em Metaphysik der Sitten Vigilantius: primeiro, mostrar que os conceitos de dever e graça não são compatíveis e que tentar juntá-los implica em comprometer-se com uma concepção ética defeituosa; segundo, mostrar que uma concepção ética, como aquela apresentada em A fundamentação da metafísica dos costumes, que sustenta que apenas a lei moral seria aceita como principium dijudicationis e o respeito pela lei moral como principium executionis da ação moral não implica em comprometer-se com uma ética ascética monástica e nem com uma concepção de ética baseada em uma lei positiva e estranha. Quanto ao segundo ponto, sustento que a resposta mais detalhada de Kant à acusação do comprometimento com uma ética monástica é apresentada apenas na Tugendlehre. Quanto ao primeiro ponto, é importante observar que sustentar que uma visão que busca conciliar dever e graça implica em uma concepção ética defeituosa, não exclui a possibilidade de reconhecer que sentimentos morais e patológicos tenham papel relevante na reflexão moral. O que Kant de fato faz em A metafisica dos costumes, embora seja um papel muito menor do que aquele que Schiller pretende conceder as inclinações com seu conceito de graça, na figura da bela alma.

\section{As diferenças entre as concepções éticas de Kant e Schiller}

Baxley acredita que, apesar de tentativas como a de Beiser de aproximar as posições de Schiller e Kant a respeito da filosofia moral, ainda permanecem diferenças residuais relevantes (2008, p. 9). Schiller e Kant possuem distintos conceitos de virtude. A noção de virtude de Kant está vinculada com a noção de liberdade interna como autocracia, ao passo que a concepção de virtude de Schiller implica cumprir o que o dever moral exige "como se fosse" por instinto e com prazer (Baxley 2008, p. 9). Kant, de certa forma, reconhece que virtude e prazer podem estar relacionados, mas o prazer sempre se apresenta como algo que se segue ao cumprimento da lei moral e não algo que leve a execução do que a lei moral exige. Schiller acredita que a bela alma cumpriria o dever sem percebê-lo como uma coação. Kant pensa que a lei moral sempre se apresenta na forma imperativa aos seres humanos (A. A. IV, 414). Schiller pensa que, ao menos para a bela alma, a moralidade não se apresenta na forma imperativa (Schiller 1971, p.109). A lei moral se apresenta como imperativa em Schiller apenas em circunstâncias adversas (trágicas, por exemplo), em Kant a lei moral sempre se apresenta na forma imperativa. 
Qual então seria a diferença entre as concepções morais de Kant e Schiller? Höffe (2012, p. 197) sustenta que a diferença não se encontra na ideia de uma harmonia entre a vontade moral e o sentimento moral, mas no estatuto metódico do sentimento. $\mathrm{O}$ sentimento a que Kant se refere é puramente racional: o respeito pela lei moral, ao passo que em Schiller sentimentos não morais (ou patológicos) seriam harmonizados com a lei moral e deveriam ser cultivados. Höffe também sustenta que a bela alma [schöne Seele] poderia ser compreendida, na melhor das hipóteses, como apenas um ideal [eines Ideals] na filosofia prática de Kant, mas parece uma possibilidade real na filosofia prática de Schiller (Höffe 2012, p. 197). Entretanto, defendo que a bela alma não pode ser um ideal na filosofia moral de Kant, como Höffe aqui afirma (Höffe 2012, p. 197), por que o ideal do sábio estóico diferencia-se do ideal da bela alma de Schiller e Kant recusa a possibilidade do ideal de perfeição estóica na dialética da Crítica da razão prática, exatamente por recusar que esse ideal seja realizável. A bela alma age "como se" por instinto e por inclinação, o sábio estóico age sem inclinação ou até mesmo contra a inclinação. Entretanto, Schiller claramente afirma em Sobre graça e dignidade, que a bela alma, ou beleza de caráter é apenas uma ideia [ist bloß eine Idee], que devemos buscar nos conformar, porém nunca podemos alcançar, ou seja, até mesmo Schiller reconhece textualmente, ao menos duas vezes que o ideal de beleza moral é apenas uma ideia, que na prática sempre ocorre o predomínio de um dos dois impulsos, o racional ou o sensível. Aqui surge a pergunta: Höffe desconhece essas passagens em que Schiller deixa claro que a bela alma seria apenas um ideal ou ele estaria pensando em algum outro elemento na posição de Schiller que torne a hipótese interpretativa do mesmo estar comprometido com uma possibilidade real da bela alma? Talvez Höffe quisesse aqui chamar a atenção à ambiguidade da posição de Schiller a respeito da possibilidade de se alcançar o ideal de uma bela alma, dado que Schiller busca desenvolver uma educação estética do ser humano, mediante a qual, o ser humano poderia alcançar esse ideal de beleza moral.

\section{Considerações Finais}

À luz da reconstrução do debate entre Kant e Schiller a respeito do papel das inclinações nas ações com valor moral é possível melhor compreender o papel das inclinações na filosofia moral de ambos os filósofos. Contrariamente ao que o epigrama, 
denominado escrúpulos da consciência, possa sugerir. As inclinações não são um indício do valor moral das ações nem em Kant, nem em Schiller, embora as inclinações ocupem um papel importante na beleza moral em Schiller. O ideal de beleza moral de Schiller contém uma figura, a bela alma, em que inclinação e dever seriam harmonizados, em que graça e dever seriam harmonizados. Além disso, mesmo que Schiller sustente que o espírito da ética de Kant não está comprometido com uma moral ascética monástica e com uma concepção de lei moral positiva e estranha, não se pode ignorar que a forma como Kant apresenta sua concepção moral de fato dá espaço às vezes a esse tipo de interpretação, ao menos nas obras da década de 1780. Razão pela qual Kant procura responder a esse tipo de objeções visando mostrar que sua concepção ética não pode ser identificada com uma moral ascética monástica e que a lei moral não é algo positivo e estranho. Além do mais, Kant procura mostrar que uma ética que procura harmonizar dever e inclinação da maneira que Schiller pretende não seria factível. Não seria possível conciliar dever e graça. Por fim, se poderia acrescentar que Schiller discorda da concepção imperativa da ética de Kant, ao menos que a ética se apresente sempre na forma imperativa. Kant, por sua vez, compreende que a noção de obrigação vincula-se com a de necessidade incondicional, por conseguinte a ética sempre se apresenta na forma imperativa. Como diz Baxley (2008, p. 11), "Schiller discorda de Kant que a mera capacidade de realizar uma ação contra a moral ou a mera capacidade de transgredir a lei moral seja suficiente para que a ética se apresente na forma imperativa". Entretanto, não parece se tratar apenas de uma diferença entre uma posição pessimista e uma otimista entre os dois filósofos, como ressalta Höffe (2012, p. 196), mas algo que se segue da perspectiva antropológica mais realista quanto às capacidades humanas de Kant. Razão pela qual se defende aqui que Kant pode compreender a ética de Schiller como um tipo de ética defeituosa [ethica deceptrix], dado que aquilo que sua concepção moral exige parece desproporcional aos poderes e à natureza humana. 


\section{Notas:}

${ }^{1}$ Professor Adjunto C de Filosofia da Universidade Estadual de Londrina e do Programa de Pósgraduação em Filosofia da Universidade Estadual de Londrina (UEL), Londrina, PR. Brasil. e-mail: charlesfeldhaus@yahoo.com.br

${ }^{2}$ Esse estudo é resultado de minha pesquisa de pós-doutorado junto à Marthin-Luther-Universtität HalleWittenberg sob supervisão do Professor Heiner F. Klemme financiada pela CAPES entre agosto de 2014 e julho de 2015.

${ }^{3}$ Todas as citações de Kant são da edição da academia. Todas as traduções das obras de Schiller, Kant e dos comentadores são minhas. 


\section{Referências bibliográficas:}

Barbosa, Ricardo. 2005. A especificidade do estético e a razão prática em Schiller. Kriterion. 112: 229-242.

Baxley, Anne Margaret. 2008. Pleasure, Freedom and Grace: Schiller s Completion Kant s Ethics. Inquiry: an Interdisciplinary Journal of Philosophy. 51: 1, 1-15.

Baxley, Anne Margaret. 2010. Kant's Theory of Virtue. The Value of Autocracy. Cambridge: Cambridge University Press.

Beiser, Frederick. 2005. Schiller as Philosopher: a Re-examination. Oxford: Oxford University Press.

Dörflinger, Bernd. Ethische Methodenlehre: Didaktik und Asketik. In: Trampota, Andreas. \& Sensen, Oliver. \& Timmermann, Jens. 2013. Kant's „Tugendlehre“ $A$ Compreensive Commentary. De Gruyter: Berlin, p. 383-410.

Höffe, Otfried. 2012. Provokation 2: Pflicht kontra Neigung? In: HÖFFE, Otfried. Kants Kritik der praktischen Vernunft. Eine Philosophie der Freiheit. Beck: München, p. 187-197.

Horn, Christoph \& Mieth, Corinna. 2007. Immanuel Kant Grundlegung zur Metaphysik der Sitten. Suhrkamp: Frankfurt.

Kant, I. 1968. Kants Werke. Akademie Berlin, Walter de Gruyter \& Co.

Schiller, Friedrich. 1955. Gesammelte Werke. Herausgegeben von Reinhold Netolitzsky. Deutschland: Berltesmann.

Schiller, Friedrich. 1971. Kallias oder Über die Schönheit/Über Anmut und Würde. Sttugart: Reclam.

Schiller, Friedrich. 2009. Über die ästhetische Erziehung des Menschen in einer Reihe von Briefen. Frankfurt: Suhrkamp.

Schopenhauer, Arthur. 2007. Über die Grundlage der Moral. Frankfurt: Meiner.

Schönecker, Dieter. \& Wood, Allen. W. 2002. Kant „,Grundlegung zur Metaphysik der Sitten “. Ein einführender Kommentar. Ferdinand Schönigh: Padeborn.

Winegar, Reed. 2013. An Unfamiliar and Positive Law: On Kant and Schiller. Archiv für Geschichte der Philosophie, 95, 3, 275-297. 